\title{
COMPARATIVE ANALYSIS ON NUMERICAL MODELLING AND EXPERIMENTS OF THE CUTTING TEMPERATURE IN MAGNETIC ABRASIVE FINISHING PROCESS
}

\author{
Dr. Ali H. Kadhum \\ kadhumali59@yahoo.com \\ Baghdad University- Al-Khwarizmi College of Engineering- Automated Manufacturing \\ Engineering Department-Al-Jadriia, Baghdad, Iraq
}

\begin{abstract}
In Magnetic Abrasive Finishing (MAF) process the cutting temperature is generated from two sources, from the electromagnetic flux (electrical heat), and from magnetic abrasive brush due to the friction force (mechanical heat). The cutting temperature has significant effects upon the condition of the surface, whereas it is less studied than the other parameters.

In this study, an attempt has been made to simulate and investigate the influence of cutting parameters on the cutting temperature, to improve the thermal effect by MAF process. The aims of this study was to determine the distribution of the cutting temperature in the working gap, numerically and experimentally, then compared the results. In addition, to determine the most influence parameters affecting on the cutting temperature for Brass alloy $\mathrm{CuZn} 28$.

Two dimensional Finite Element Models (FEM) with two software's were developed to predict the temperature by dynamic electric and magnetic field, the first was DEFORM 10.2 used to calculate the mechanical heat and the second was COMSOL $_{5.2}$ used to calculate the electrical heat. Sixteen tests designed according to Taguchi matrix through the orthogonal array (OA) L16 $\left(4^{4}\right)$. There are four various parameters that, have a large impact on cutting temperature, with four levels (rotational speed (A), working time (B), current (C), and working gap (D)). The analysis of the variance (ANOVA) technique was utilized to analysis the results, by using the statistical software (MINITAB-17).

From the results, it is concluded that the Numerical modeling gives a very good comparison with the values of experimental tests. The maximum difference between the numerical and experimental temperature for brass CuZn28 is less than (9\%).

KEYWORDS: Cutting Temperature, Magnetic Abrasive Finishing process, MINITAB-17, FEM, brassCuZn28.

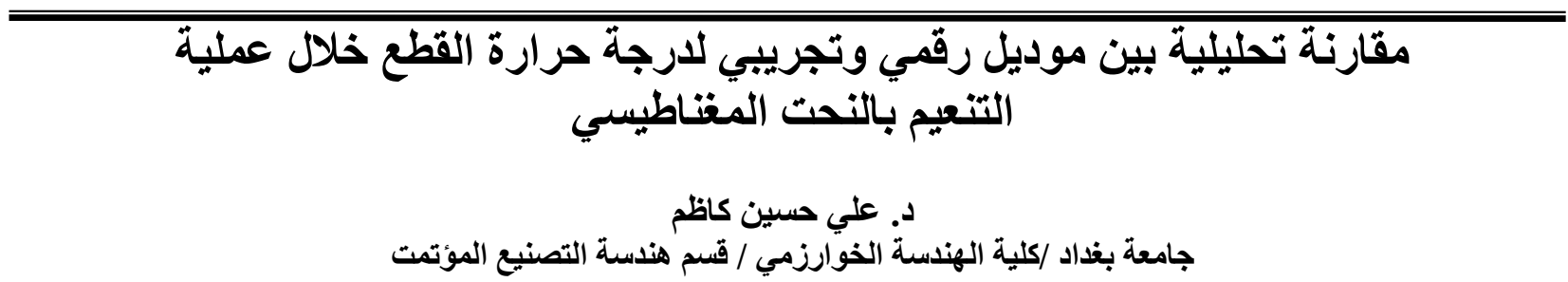

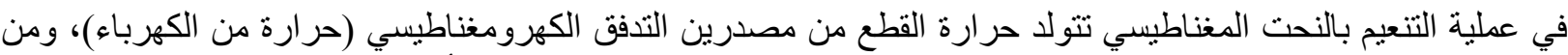

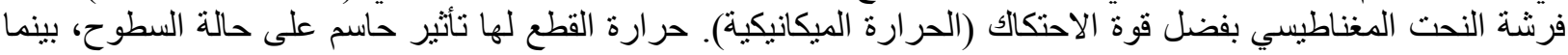
هي قليلة الدر اسة نسبة لبقية المتغيرات. 


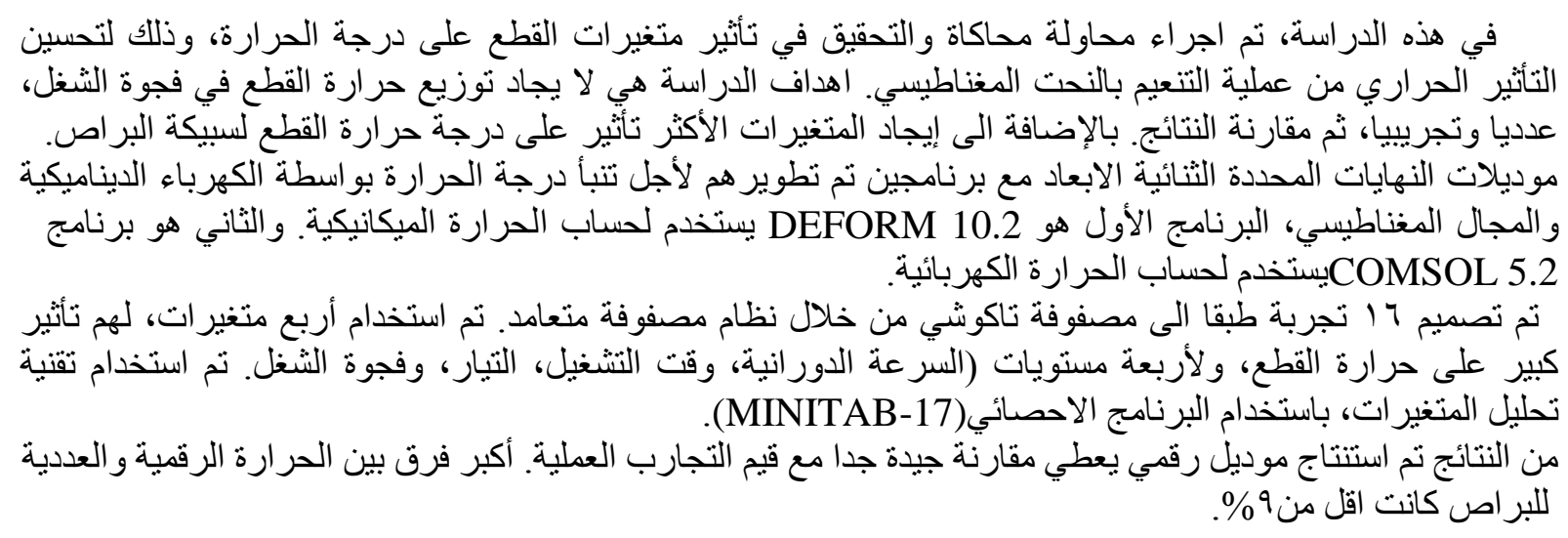

\section{INTRODUCTION}

One of the effective machining techniques is magnetic abrasive finishing of surfaces for different materials and shape. In this method, the workpiece is fixed between the two poles of a magnet; the working gap between the workpiece and the poles is filled with magnetic abrasive particles. A magnetic abrasive flexible brush is formed, acting as a multipoint cutting tool, due to the effect of the magnetic field in the working gap as shown in Figure(1), TaeWan Kim [2010]. Magnetic abrasive finishing process is able to produce surface roughness of nanometer range on flat surfaces, Yan Wang, and Dejin $\mathrm{Hu}$ [2005]. In magnetic abrasive finishing (MAF) method, a magnetic field is used to generate cutting and polishing forces to treat the surface of a machined part. The magnetic field behaves as an elastic bond for the abrasive ferromagnetic grains and allows more effective use of the abrasive's cutting edges, furthermore, it provides conditions for a small cutting force and a low surface temperature for finishing operations, K. A. Gogaev,1 V. V. Nepomnyashchii,1 T. V. Mosina,1 I. P. Neshpor,1 and .Leonowicz1 [2006]. The MAF method offers a number of advantages over the conventional techniques of abrasive treatment: (i) Instantaneous temperature spikes can be readily avoided. (ii) The cutting temperature can be lowered to $473 \mathrm{~K}$. (iii) The force (typically up to $1 \mathrm{MPa}$ ) at which the abrasive grains act on the surface treated promotes the formation of a new high-disperse phase and converts the tensile stresses into compressive, $\mathrm{Yu}$. M. Baron [1975], A. N. Reznakov [1977], K. A. Gogae, V. V. Nepomnyashchii, T. V. Mosina, I. P. Neshpor, M. Leonowicz Singh [2006]. Vivek Mishra et al. [2014] determining work-brush interface temperature in magnetic abrasive finishing process. They are used ANSYS software to model and simulate magnetic field distribution, magnetic pressure and temperature distribution at work-brush interface during the process. Transient thermal analysis of work piece domain has been performed to predict the temperature rise due to frictional heat flux and magnetic flux density of current in electromagnet coil. The predicted temperature on work-brush interface was founded in the range of $34-51{ }^{\circ} \mathrm{C}$. Hou et al. [1998] presented the thermal aspect of magnetic abrasive finishing of a ceramic roller using the bonded type of Magnetic Abrasive Powders. Chandan gaur [2015] study the magnetic abrasive finishing as finishing tool in the internal tube, and the effect of the amount heat generation in the machining process especially in the point between the cutting tool and the workpiece, which caused subsurface damage. Chandan gaur applied the voltage and the working gap as parameter, and use MINITAB17 to obtained regression model to analysis the data, the result show that the temperature increase with increased the voltage and decreased the machining gap. The maximum temperature during the magnetic abrasive finishing process was $94.7^{\circ} \mathrm{C}$. 
Alloy steel is taken as the work piece, and the conditions of finishing as the following: the table feed of $8.00 \mathrm{~mm} / \mathrm{min}$. One complete cycle involved movement of the table from the starting point to a distance of $20.0 \mathrm{~mm}$ forward and then $20.0 \mathrm{~mm}$ backward. The rotational speed of the magnet was fixed at 200RPM. The homogenous mixture of unbounded magnetic abrasive particles was prepared just before the start of each experiment in the ratio of $75 \%$ iron particles (mesh no. 300), and $25 \%$ SiC (mesh no. 1000) particles by weight. Then, $3 \%$ lubricant (SAE-30). According to the MAF process condition, the temperature in the working gap is generated from two sources: mechanical heat due to friction that produced from the effect of friction in the contact surface and electrical heat due to electromagnetic flux density, which produce from the current in the coil. It is important to find an actual measure for the temperature of these two sources that influences the temperature rise in the working gap as shown in the equation (1).

$\mathrm{T}_{\text {working zone }}=\mathrm{T}_{\text {mechanical }}+\mathrm{T}_{\text {electrical }}$

From the above literature survey, it can be concluded that, very little effort has been made toward the modeling of the temperature during the MAF process. This study presents finite element based code, which has been developed to evaluate the distribution of temperature in the working zone, considering current in the coil, working time, working gap, and rotation of the poles as the main parameters.

\section{EXPERIMENTAL WORK OF MAF PROCESS}

In the MAF process, an electromagnetic inductor was manufactured because it plays an important role in the finishing the surface. The inductor consists of the following: the core from the low carbon steel, the diameter of core is $20 \mathrm{~mm}$, the length of the core is $280 \mathrm{~mm}$ while the diameter wire of coil is $0.9 \mathrm{~mm}$; number of turns is 2400 for primary and 1600 for the secondary coil. The tests were performed on the conventional" vertical Milling Machine Model: MDM 4VS/4HS/4S" its spindle is used to fixed the inductor. The dimensions of the flat workpiece were $(100 \times 50 \times 3) \mathrm{mm}$. Before MAF process, the weight of the workpiece is measured before the beginning of the experiment. The workpiece is fixed by a special fixture on the machine's table. The abrasive powder includes $100 \mathrm{gm}$ of Iron powder with $50 \mathrm{gm}$ of tungsten carbide with $200 \mu \mathrm{m}$ mesh size. Thermocouples K-type were used experimentally to measure the temperature in the working zone. The thermocouples were fixed to allow the measurement of the temperature fields, in the two holes, the distribution of the temperature in the working zone is shown in Figure(2).

\section{Selection of Cutting Parameters And Their Levels}

In the MAF process four parameters were selected, the rotational speed, working time, current in the coil, and working gap with four levels for each parameter. The selection of parameters and their levels are based on the preliminary experiments, and are summarized in Table 1. Brass alloy CuZn28 was selected as workpiece material.

\section{Selection of The OA Experiment}

The experiments were designed based on the orthogonal array (OA). Technique to reduce the number of the experiments. From the MINITAB-17 software and by total degree of the freedom (DOF) need to be computed, in order the select of the appropriate OA for the experiments, each variable with four levels has two degree of the freedom. As per Taguchi 
method the total DOF of selecting OA must be greater than or equal to the total DOF required for the experiment. therefore an orthogonal array L16 $\left(4^{4}\right)$ for the four factors with the four levels is used in the present investigation to perform the most effective experiments, sixteen different tests from the overall experiment 256 that is designed based on the Taguchi OA L16 were shown in Table 2.

\section{FINITE ELEMENT MODELS TO DETERMINE THE CUTTING TEMPERATURE}

To evaluate the thermal effect, a computer simulation was conducted. The temperature characteristics concerned in this study were the distribution and the maximum magnitude of temperature on the working zone. Finite element method has been used to calculate and analyzing the thermal distribution, so the temperature can be predicting without the experiment. Heat has critical influence on the finishing surface by removing the material and so hard to predict the distribution of the temperature. The change in the temperature during the process effects the dimensions of the workpiece. There are two software's of thermal effects in MAF process, DEFORM Software used to calculate the mechanical temperature and COMSOL Software to calculate the electrical temperature.

\section{Deform software}

DEFORM-3D ${ }^{\mathrm{TM}} 10.2$ is one of the commercial FEM software that used to analysis different condition, which include a various process, a LaGrange implicit code was used to simulate the dimensional MAF process of Brass alloy CuZn-28. A finite element model was developed for the MAF process. The assumption of the MAF process with DEFORM 10.2 is used two parameters (working gap, rotational speed) and considered the magnetic abrasive powder as rigid cutting tool (powder with current). This model was composed the workpiece and powder, as shown in figure(3). The automatic mesh generator was applied with a higher mesh density near the contact zone of the workpiece in order to obtain results that are more accurate. The workpiece was meshed with 10052 nodes. In addition, the tool material was selected as tungsten carbide with iron. The tool was modeled with 25946 elements, 5611 nodes. The amount of heat Q depends on the heat generation rate per control volume unit per unit time. The values of generated heat are obtained from the force and velocity factors along shear and friction dimensions as shown in equation (2).

$$
Q_{f}=F_{f} V_{c}
$$

$F_{f}$ : Frictional force between the magnetic abrasive powder and workpiece $(\mathrm{N})$.

$V_{C}$ : The cutting velocity $(\mathrm{m} / \mathrm{min})$.

\section{COMSOL Software}

COMSOL $_{5.2}$ is one of the software that based on the numerical method; with COMSOL can be solved different types of the scientific problem's engineering. COMSOL include different branches such as mechanical, chemical fluid flow, and chemical applications. In the model builder, the model tree gives full overview of the model and access to all function geometry, physics settings, mesh, boundary conditions, studies, solvers, post processing, and visualizations. The assumption of the MAF process with COMSOL $_{5.2}$ is used two parameters (current, working time). The magnetic field is produced by electric current pass in the closed 
loop, in the COMSOL software the fundamentals of the magnetic field is based on the Maxwell's equations as the equation (3), the Maxwell's equations are a set of equations described the electromagnetic field.

$$
\nabla\left(\mu^{-1} \mu_{r}^{-1} B\right)-\sigma_{v} B=J_{e}
$$

$\mathrm{B}=\nabla \times A$

$$
\mathrm{H}=\left(\mu^{-1} \mu_{\mathrm{r}}^{-1} \mathrm{~B}\right)
$$

$\mathrm{H}$ : is the magnetic field intensity

$\mu$ : Permeability $(\mathrm{H} / \mathrm{m})$;

$\mu_{\mathrm{r}}$ : Permeability relative $(\mathrm{H} / \mathrm{m})$

B: magnetic induction $\left(\mathrm{W} / \mathrm{mm}^{2}\right)$;

$\sigma_{v}:$ Vector electrical conductivity

$\mathrm{J}_{\mathrm{e}}$ : Current density $\left(\mathrm{A} / \mathrm{mm}^{2}\right)$

\section{RESULT AND DISCUSSIONS}

ANOVA Technique. In order to investigate the effect of parameters on the cutting temperature of the MAF process, analysis of variance was performed on the numerical and experimental by the statically software (Minitab TM 17). Additionally, the factor $\mathrm{F}$ ratio used to determine which parameter has a significant effect on the temperature. The results of cutting temperature numerically and experimentally are presented in Table 3.

\section{Analysis of The Cutting Temperature According to Cutting Parameters}

In this study, the results of the cutting temperature tests for Brass alloy $\mathrm{CuZn} 28$ are analysis by ANOVA, which corresponded to the largest $F$ ratio. It is clear from the ANOVA Table 4 numerically and experimentally, that the working gap (D) has less percentage of contribution on the temperature compared to the others parameters. The computed values of F-ratio and contributions for parameter (B) and (C) are more significant on the cutting temperature then followed by the rotational speed (A) and the working gap (D). However, there is a less significant difference between experimental and numerical tests. The developed regression equations and correlation coefficients are summarized in Table 5. The coefficient of correlation indicates that the regression models provides very good relationship between the experiment and numerical parameters, the two models are statistically significant level. The main effect plots of parameters for experiment and numerical are shown in figure(4) and figure(5) respectively. It is revealed that as the working time and current increases the cutting temperature also increases, due to the heat generation in the contact zone, while increasing the rotational speed cause to increase the cutting temperature. Further increasing the speed decreases the cutting temperature; this is due to centrifugal speed, causes to decrease the amount of powders in the working zone. It is observed from figure(4) and figure(5), that the working gap has no effect on the temperature. The average value for the two-measured point of the temperature from the electrical source of the brass in the working zone is (332k) equal to $59^{\circ} \mathrm{C}$, the temperature in the electrical part is building by using COMSOL software, see fig. 6. While the temperature of the mechanical heating in the brass is $35.5^{\circ} \mathrm{C}$ the temperature in the mechanical part is determined with DEFORM as shown in the fig. 7. the temperature of the boundary condition $\left(20^{\circ} \mathrm{C}\right)$ so the amount of the temperature in the working zone is become as shown in Table 6. From figure. (8), it's noticed that there are founded closer points 
for the experimental and numerical temperature at the same levels of the parameters. The difference between the points of the numerical and experimental temperature for brass is $9 \%$.

\section{CONCLUSIONS}

From the previous results can be concluded:

1. Finite Element Models (FEM) with two software's were developed to predict the temperature by dynamic electric and magnetic field, the first was DEFORM ${ }_{10.2}$ used to calculate the mechanical heat and the second was $\mathrm{COMSOL}_{5.2}$ used to calculate the electrical heat.

2. Numerical modeling gives satisfactory result compared with experimental tests. . The maximum difference between the numerical and experimental temperature for brass $\mathrm{CuZn} 28$ is less than $(9 \%)$.

3. From the analysis of the variance noticed that the cutting time (B) and current (C) was significant effect on the cutting temperature.

4- Increasing the Cutting time (B) and current (C) cause to increase the temperature for brass alloy CuZn28.

Figures and tables

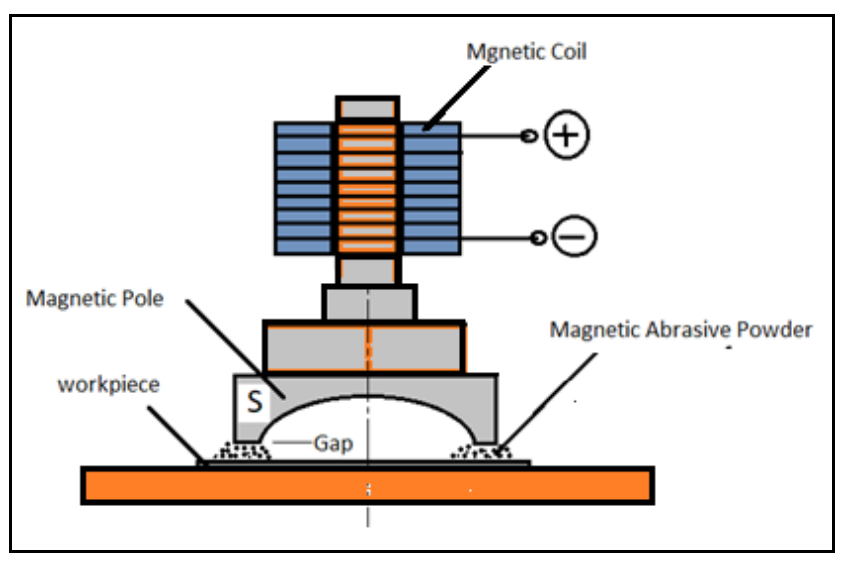

Figure 1: Schematic of the working principle of MAF 


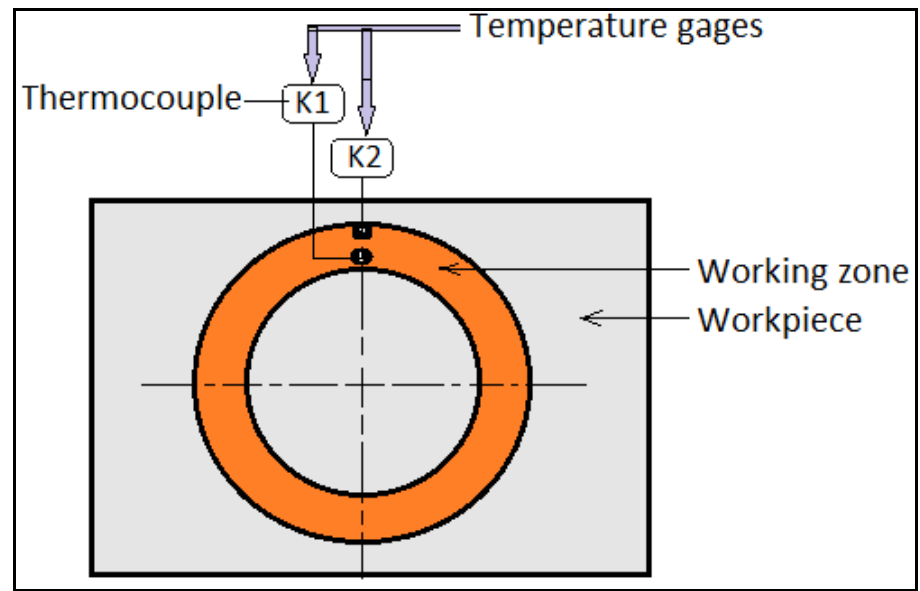

Figure 2: Schematic measurement of temperature by thermocouple

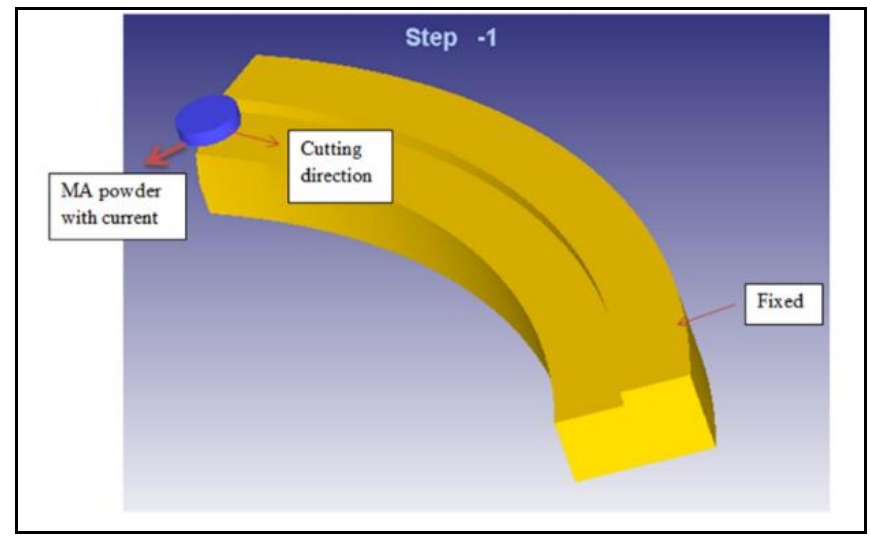

Figure 3: Model of MAF operation by DEFORM software

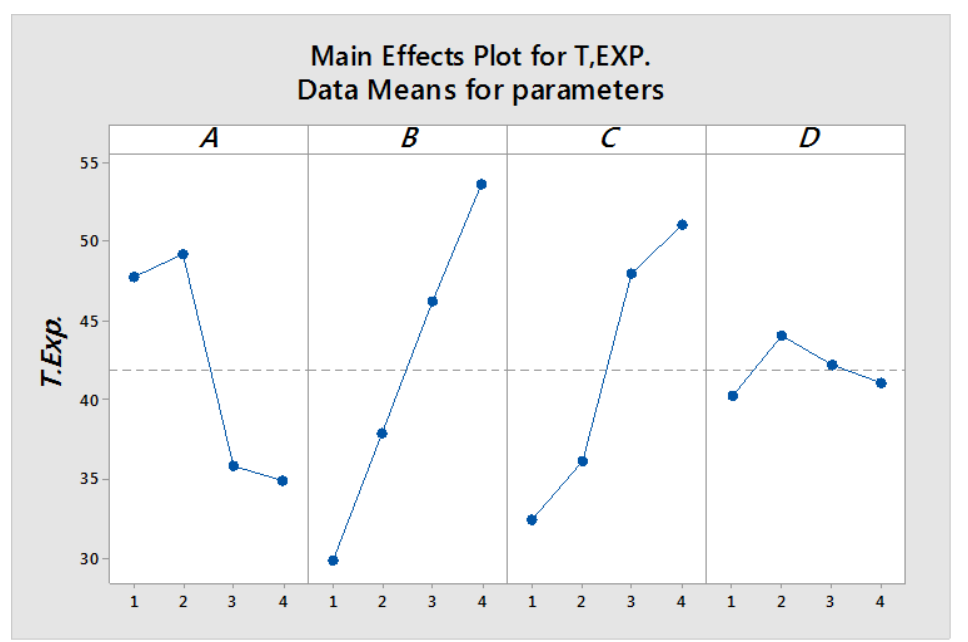

Figure 4: Main effect plot for experimental temperature 


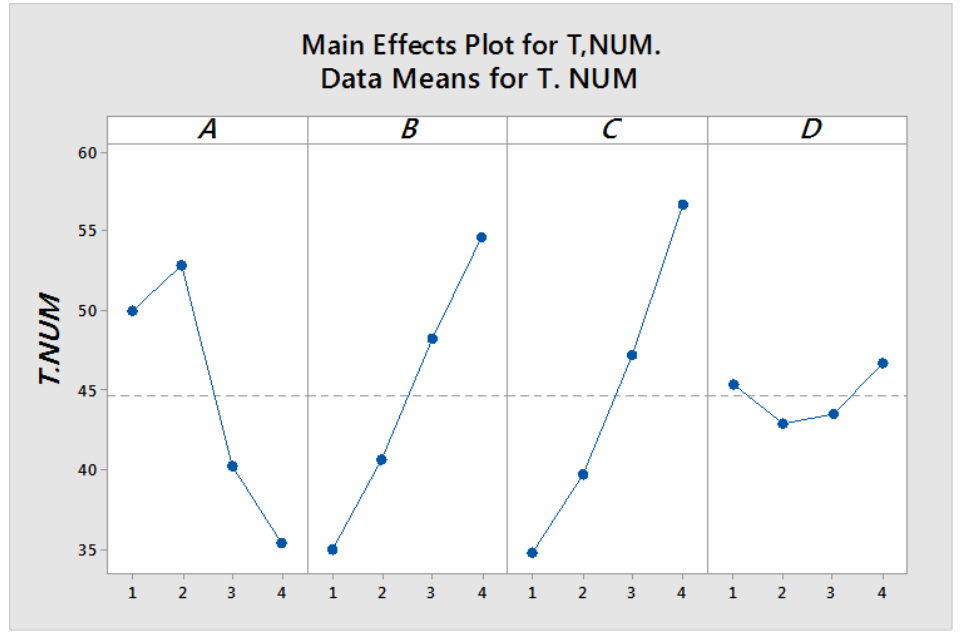

Figure 5: Main effect plot for numerical temperature

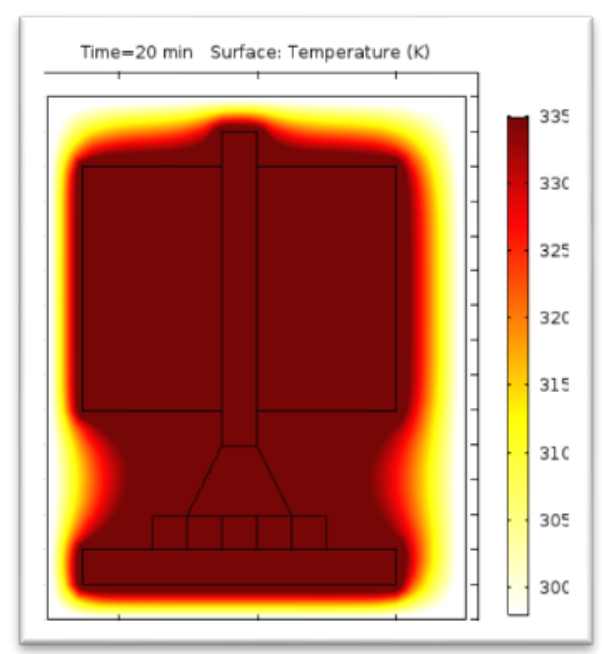

Figure 6: The temperature of brass obtained from current numerically.

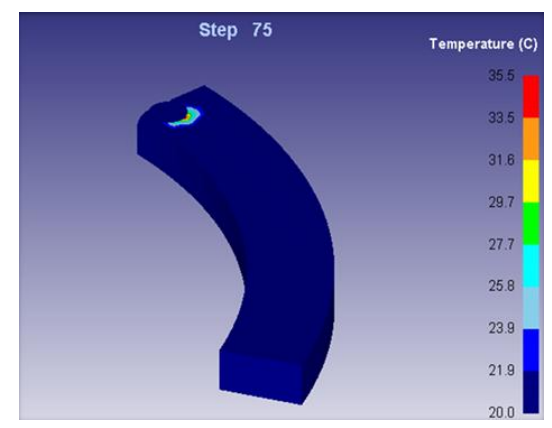

Figure 7: The temperature by DEFORM soft ware 


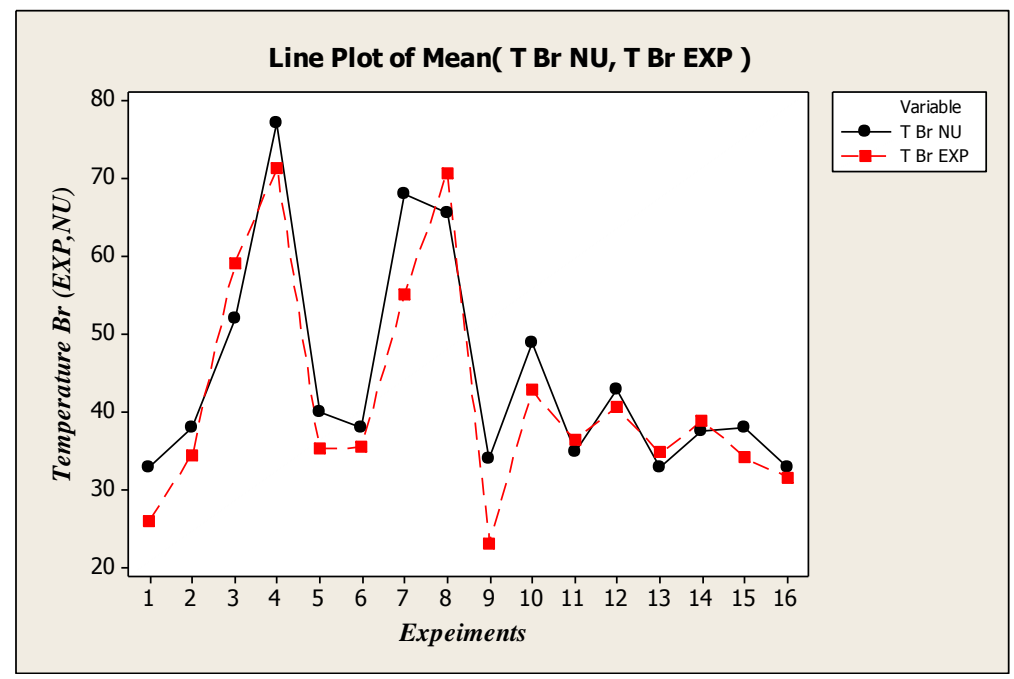

Figure 8: The numerical and experimental temperature of the brass

Table 1. Cutting parameters and their levels

\begin{tabular}{|l|l|l|r|r|r|r|r|}
\hline & \multirow{2}{*}{ No. } & \multirow{2}{*}{ Parameters } & \multirow{2}{*}{ Unit } & \multirow{2}{*}{ Symbol } & \multicolumn{4}{|c|}{ Parameters levels } \\
\cline { 5 - 8 } & & & & $(1)$ & $(2)$ & $(3)$ & $(4)$ \\
\hline $\mathbf{1}$ & Rotational speed & rpm & A & 240 & 560 & 720 & 1000 \\
\hline $\mathbf{2}$ & Working time & min & B & 7 & 12 & 17 & 22 \\
\hline $\mathbf{3}$ & Current in the coil & amp & C & 1 & 1.5 & 2 & 2.5 \\
\hline $\mathbf{4}$ & Working gap & mm & D & 0.75 & 1 & 1.25 & 1.5 \\
\hline
\end{tabular}


Table 2: Experimental plan using OA L16 (4 $\left.4^{4}\right)$

\begin{tabular}{|c|c|c|c|c|c|c|c|c|c|c|c|c|c|c|c|c|c|}
\hline No. & $\begin{array}{c}\mathrm{A} \\
\mathrm{cod} \\
\mathrm{rpm}\end{array}$ & $\begin{array}{l}\text { A } \\
\text { Un } \\
\text { cod }\end{array}$ & $\begin{array}{l}\mathrm{B} \\
\mathrm{cod} / \mathrm{m} \\
\text { in }\end{array}$ & $\begin{array}{l}\text { B } \\
\text { Un } \\
\text { cod }\end{array}$ & fod/ & $\begin{array}{l}\text { C } \\
\text { Un } \\
\text { cod }\end{array}$ & $\begin{array}{l}\mathrm{D} \\
\mathrm{cod} / \\
\mathrm{mm}\end{array}$ & $\begin{array}{l}\text { D } \\
\text { Un } \\
\text { cod }\end{array}$ & No. & $\begin{array}{l}\text { A } \\
\text { cod }\end{array}$ & $\begin{array}{l}\text { A } \\
\text { Un } \\
\text { cod }\end{array}$ & $\begin{array}{l}\text { B } \\
\text { cod }\end{array}$ & $\begin{array}{l}\text { B } \\
\text { Un } \\
\text { cod }\end{array}$ & $\begin{array}{l}\text { C } \\
\operatorname{cod}\end{array}$ & $\begin{array}{l}\text { C } \\
\text { Un } \\
\text { cod }\end{array}$ & $\begin{array}{l}\mathrm{D} \\
\operatorname{cod}\end{array}$ & $\begin{array}{l}\text { D } \\
\text { Un } \\
\text { cod }\end{array}$ \\
\hline 1 & 1 & 240 & 1 & 7 & 1 & 1 & 1 & 0.75 & 9 & 3 & 720 & 1 & 7 & 3 & 2 & 4 & 1.5 \\
\hline 2 & 1 & 240 & 2 & 12 & 2 & 1.5 & 2 & 1 & 10 & 3 & 720 & 2 & 12 & 4 & 2.5 & 3 & 1.25 \\
\hline 3 & 1 & 240 & 3 & 17 & 3 & 2 & 3 & 1.25 & 11 & 3 & 720 & 3 & 17 & 1 & 1 & 2 & 1 \\
\hline 4 & 1 & 240 & 4 & 22 & 4 & 2.5 & 4 & 1.5 & 12 & 3 & 720 & 4 & 22 & 2 & 1.5 & 1 & 0.75 \\
\hline 5 & 2 & 560 & 1 & 7 & 2 & 1.5 & 3 & 1.25 & 13 & 4 & 1000 & 1 & 7 & 4 & 2.5 & 2 & 1 \\
\hline 6 & 2 & 560 & 2 & 12 & 1 & 1 & 4 & 1.5 & 14 & 4 & 1000 & 2 & 12 & 3 & 2 & 1 & 0.75 \\
\hline 7 & 2 & 560 & 3 & 17 & 4 & 2.5 & 1 & 0.75 & 15 & 4 & 1000 & 3 & 17 & 2 & 1.5 & 4 & 1.5 \\
\hline 8 & 2 & 560 & 4 & 22 & 3 & 2 & 2 & 1.25 & 16 & 4 & 1000 & 4 & 22 & 1 & 1 & 3 & 1.25 \\
\hline
\end{tabular}


Table 3: Numerical and Experiments results of cutting temperature

\begin{tabular}{|c|c|c|c|c|c|c|}
\hline $\begin{array}{l}\text { No. } \\
\text { Exp. }\end{array}$ & $\mathrm{A}$ & B & $\mathrm{C}$ & $\mathrm{D}$ & $\begin{array}{l}\text { T, EXP. } \\
\left({ }^{\circ} \mathrm{C}\right)\end{array}$ & $\begin{array}{l}\text { T,NUM } \\
\left({ }^{\circ} \mathrm{C}\right)\end{array}$ \\
\hline 1 & 1 & 1 & 1 & 1 & 26.1 & 33.0 \\
\hline 2 & 1 & 2 & 2 & 2 & 34.5 & 38.0 \\
\hline 3 & 1 & 3 & 3 & 3 & 59.1 & 52.0 \\
\hline 4 & 1 & 4 & 4 & 4 & 71.4 & 77.0 \\
\hline 5 & 2 & 1 & 2 & 3 & 35.3 & 40.0 \\
\hline 6 & 2 & 2 & 1 & 4 & 35.5 & 38.0 \\
\hline 7 & 2 & 3 & 4 & 1 & 55.1 & 68.0 \\
\hline 8 & 2 & 4 & 3 & 2 & 70.7 & 65.6 \\
\hline 9 & 3 & 1 & 3 & 4 & 23.2 & 34.0 \\
\hline 10 & 3 & 2 & 4 & 3 & 42.8 & 49.0 \\
\hline 11 & 3 & 3 & 1 & 2 & 36.4 & 35.0 \\
\hline 12 & 3 & 4 & 2 & 1 & 40.7 & 43.0 \\
\hline 13 & 4 & 1 & 4 & 2 & 34.8 & 33.0 \\
\hline 14 & 4 & 2 & 3 & 1 & 38.9 & 37.5 \\
\hline 15 & 4 & 3 & 2 & 4 & 34.2 & 38.0 \\
\hline 16 & 4 & 4 & 1 & 3 & 31.6 & 33.0 \\
\hline
\end{tabular}


Table 4: ANOVA table of Experiment for Cutting Temperature

\begin{tabular}{|c|c|c|c|c|c|c|}
\hline Parameters & DOF & Sum of Squares (ss) & Mean Sum of Squares (MS) & F-Value & P- Value & $\begin{array}{c}\text { Contribution } \\
(\%)\end{array}$ \\
\hline \multicolumn{7}{|c|}{ 1. Experimental Tests } \\
\hline Rotational Speed (A) & 1 & 542.36 & 542.36 & 13.49 & 0.004 & 17.132 \\
\hline Working Time (B) & 1 & 1264.85 & 1264.85 & 31.45 & 0.00 & 39.956 \\
\hline Current $\quad(\mathrm{C})$ & 1 & 915.98 & 915.98 & 22.78 & 0.001 & 28.934 \\
\hline Working Gap (D) & 1 & 0.11 & 0.11 & 0.00 & 0.960 & 0.000 \\
\hline Error & 11 & 442.38 & 40.22 & & & 13.975 \\
\hline Total & 15 & 3165.67 & & & & 100.00 \\
\hline \multicolumn{7}{|c|}{ 2. Numerical Tests } \\
\hline Rotational Speed (A) & 1 & 639.02 & 639.02 & 22.36 & 0.001 & 21.84 \\
\hline Working Time (B) & 1 & 886.45 & 886.45 & 31.02 & 0.000 & 30.3 \\
\hline Current & 1 & 1081.19 & 1081.19 & 37.84 & 0.000 & 36.958 \\
\hline Working Gap (D) & 1 & 4.47 & 4.47 & 0.16 & 0.7 & 0.152 \\
\hline Error & 11 & 314.32 & 28.57 & & & 10.744 \\
\hline Total & 15 & 2925.43 & & & & 100.00 \\
\hline
\end{tabular}

Table 5: Regression Equations for experiment and numerical temperature

\begin{tabular}{|l|l|l|l|}
\hline $\mathrm{N}^{\mathrm{O} .}$ & Response & \multicolumn{1}{|c|}{ Regression Equation } & Coefficient of Correlation \\
& & & \\
\hline 1 & Temperature from Exp. & & \\
\hline 2 & Temperature from Num. & $\mathrm{T}_{\text {EXP. }}=17.93-5.21 \mathrm{~A}+7.95 \mathrm{~B}+6.77 \mathrm{C}+0.07 \mathrm{D}$ & $86.03 \%$ \\
\hline
\end{tabular}

Table 6: Determination the numerical temperature

\begin{tabular}{|c|c|c|}
\hline Electrical temperature & Mechanical temperature & The amount of temperature \\
\hline $59^{\circ} \mathrm{C}\left(\right.$ with $\left.20^{\circ} \mathrm{C}\right)$ & $35.5^{\circ} \mathrm{C}\left(\right.$ with $\left.20^{\circ} \mathrm{C}\right)$ & $74.5^{\circ} \mathrm{C}$ \\
\hline
\end{tabular}




\section{REFERENCES}

- A. N. Reznakov (ed.), Abrasive and Diamond Machining Technology [in Russian], Mashinostroenie, Moscow (1977).

- Chandan Gaur and Dr. D.K. Singh "The Analysis of Temperature during Magnetic Abrasive Finishing of Plane Surface“ International Journal for Scientific Research \& Development| Vol. 3, Issue 04, 2015.

- Hou ZB, Komanduri R (1998) Magnetic field assisted finishing of ceramics-on the thermal aspect of magnetic abrasive finishing of ceramic rollers. Trans ASME J Eng Ind 20:660-667

- K. A. Gogaev,1 V. V. Nepomnyashchii,1 T. V. Mosina,1 I. P. Neshpor,1 and .Leonowicz1 'SPECIAL FEATURES OF THE MAGNETIC ABRASIVE MACHINING', (Refractories and Industrial Ceramics) Vol. 47, No. 1, 2006

- Tae-Wan Kim" Application of magnetic abrasive polishing to composite materials" Journal of Mechanical Science and Technology 2010.

- Vivek Mishra, Harsha Goel, Rahul S. Mulik, P.M.Pandey. Determining work-brush interface temperature in magnetic abrasive finishing process' Journal of Manufacturing Processes, 16(2014) 248-256.

- Yan Wang, and Dejin Hu,"Study on the inner surface finishing of tubing by magnetic abrasive finishing", International Journal of Machine Tools \& Manufacture, Vol.45 (2005), pp. 43-49

- Yu. M. Baron, Technology of Abrasive Machining in a Magnetic Field [in Russian], Mashinostroenie, Leningrad (1975). 